\title{
Clinical use of antidepressant therapy and associated cardiovascular risk
}

This article was published in the following Dove Press journal:

Drug, Healthcare and Patient Safety

16 August 2012

Number of times this article has been viewed

\section{W Stephen Waring}

Acute Medical Unit, York Teaching Hospital NHS Foundation Trust, York, UK
Correspondence: W Stephen Waring Acute Medical Unit, York Hospital, Wigginton Road, York, YO32 5PE, UK $\mathrm{Tel}+4401904726276$

Email stephen.waring@york.nhs.uk

\begin{abstract}
A number of different psychotropic agents have been associated with an increased risk of cardiovascular disease, and these relationships have been difficult to interpret due to the presence of confounding factors. Recently, there has been renewed interest in the potential for certain antidepressants to cause QT prolongation, which is a predisposing factor for arrhythmia. However, the optimum means of determining QT remains contentious due to discrepancies between methods that may be readily applied in a clinical setting versus more detailed techniques during regulatory assessment. A number of different pharmacological mechanisms might explain the occurrence of adverse cardiac effects, and these differ according to the type of antidepressant agent. Emerging data indicate that citalopram exhibits a dose-effect relationship for QT prolongation. Whereas cardiotoxicity is readily apparent in the context of intentional antidepressant overdose, the occurrence of cardiac effects as a result of therapeutic administration is less certain. Pre-existing cardiac disease and other factors that independently predispose to arrhythmia are important considerations. Therefore, clinical judgment is needed to evaluate the overall risk or benefit of a particular antidepressant in any patient. Close monitoring should be considered for those at greatest risk of QT prolongation and arrhythmia.
\end{abstract}

Keywords: arrhythmia, electrocardiography, QT prolongation, selective serotonin reuptake inhibitors, torsades de pointes, tricyclic antidepressants

\section{Introduction}

Over many years, a number of different psychotropic agents have been associated with an increased risk of cardiovascular disease, particularly the occurrence of arrhythmia. There has been intense interest recently in the association between treatment with high citalopram or escitalopram dosages and prolongation of the QT interval on the electrocardiogram (ECG), and this has resulted in safety warnings being issued to prescribers by the Medicines and Healthcare Products Regulatory Authority, the US Food and Drug Administration, and other regulatory bodies. ${ }^{1,2}$ This has led to renewed interest in the relationship between various antidepressant drugs and the possible risk of arrhythmia and cardiovascular mortality. ${ }^{3}$

\section{Surrogate markers of arrhythmia risk: $\mathrm{QT}$ interval}

Whilst arrhythmia is a serious and potentially life-threatening adverse event, the rate of occurrence in patients receiving conventional therapeutic doses is low, and this presents a major challenge to its identification and study. In a recent observational community study, the rate of sudden death and ventricular arrhythmia was 3 per 1000 person years, with no discernible relationship to dose. ${ }^{4}$ To date, the relative 
safety of antidepressant use in a therapeutic setting has relied heavily on surrogate markers of arrhythmia risk. The most widely accepted of these is the QT interval, which may indicate the extent of drug binding to cardiac inward rectifier potassium channels (IKr), which are encoded by the human ether-a-go-go related gene (HERG). ${ }^{5}$ Blockade of potassium efflux from cardiac myocytes is associated with a prolonged repolarization phase and QT interval. Extreme examples are the congenital long QT syndromes where mutations affect the $I K r$ gene. ${ }^{6}$ For certain drugs, there appears to be a clear relationship between the extent of QT prolongation and the risk of developing polymorphic ventricular tachyarrhythmia known as torsade de pointes (TdP), including class $1 \mathrm{~A}$, IC, and class III antiarrhythmic drugs, namely quinidine, sotalol, flecainide, propafenone, and macrolide antimicrobials. ${ }^{7-9}$ TdP may manifest as seizure, dizziness, or syncope, and predisposes to ventricular fibrillation and sudden cardiac death. In contrast, certain drugs may cause dose-dependent QT prolongation but there is a weaker relationship with development of TdP; examples include amiodarone, and the antipsychotic agent, sertindole. ${ }^{10,11}$ Therefore, QT alone might not correspond directly to the risk of TdP. Moreover, the relationship between QT prolongation and other forms of arrhythmia is uncertain.

\section{QT measurement}

Whilst the QT interval might at first be perceived as a readily accessible measurement, there are enormous difficulties in establishing accurate and meaningful values (Figure 1). QT is subject to wide interindividual and intraindividual variability and is confounded by heart rate, autonomic tone, and electrolyte concentrations. The relationship with heart rate is complex, and has perhaps received the greatest attention of any of the confounding factors. One method for minimizing the effect of heart rate in any individual patient is to express the QT value with respect to the slope of the $\mathrm{R}-\mathrm{R}$ interval (inverse of heart rate) and QT across a range of heart rate values. ${ }^{12}$ This allows QT values to be expressed with reference to heart rate, whilst taking account of interindividual differences. This approach requires collection of data across a sufficiently wide range of heart rate values to allow construction of the QT:R-R slope, and needs to be examined prior to introducing antidepressant therapy so that any drug effect on the slope may be taken into account. This type of individualized approach lends itself readily to a controlled clinical trial setting, but may be less feasible in ECG assessment in routine clinical practice. An alternative approach is to consider QT in comparison with a populationbased QT-heart rate nomogram. ${ }^{13,14}$ The nomogram offers the advantage of being readily applied (Figure 2). However, too few clinical data exist to allow evaluation of its role in routine clinical practice.

A number of generalized formulae attempt to limit the confounding effects of heart rate, eg, those of Bazett QTc $(\mathrm{QTcB})=\mathrm{QT} /(\mathrm{R}-\mathrm{R})^{1 / 2}$ and Fridericia $\mathrm{QTcF}=\mathrm{QT} /(\mathrm{R}-\mathrm{R})^{1 / 3} \cdot{ }^{15,16}$ Some of the commonly applied formulae are presented in Table 1. These do not allow intraindividual differences to be taken into account, and are often unreliable at extremes of heart rate, particularly Bazett's formula. Moreover, the tendency for Bazett's formula to overcorrect QT for the effect of high heart rates often gives rise to apparent QT interval prolongation more than other formulae. Nonetheless, these formulae are often incorporated into electronic ECG recording devices so that QT and QTc data from automated analyses are readily available in clinical practice. Such automated methods normally incorporate a tangential measurement algorithm that may be unreliable for determining the $\mathrm{T}$ wave end, particularly where the T wave is of low amplitude. For the purposes of regulatory investigation, a thorough QT study

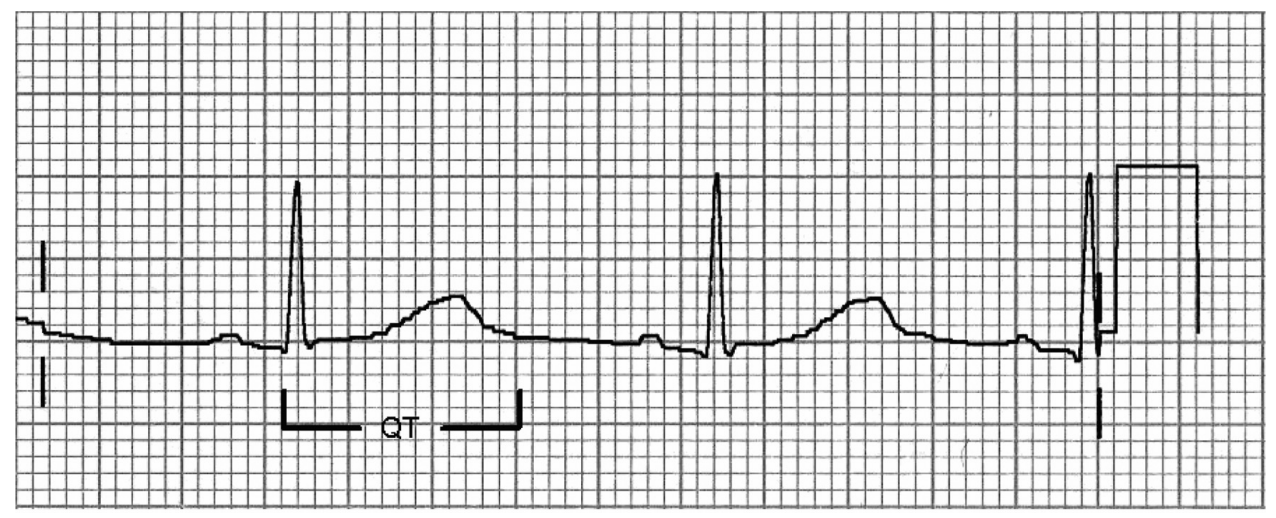

Figure I Schematic representation of the QT interval, which extends from the start of the QRS complex to the end of the T wave. 


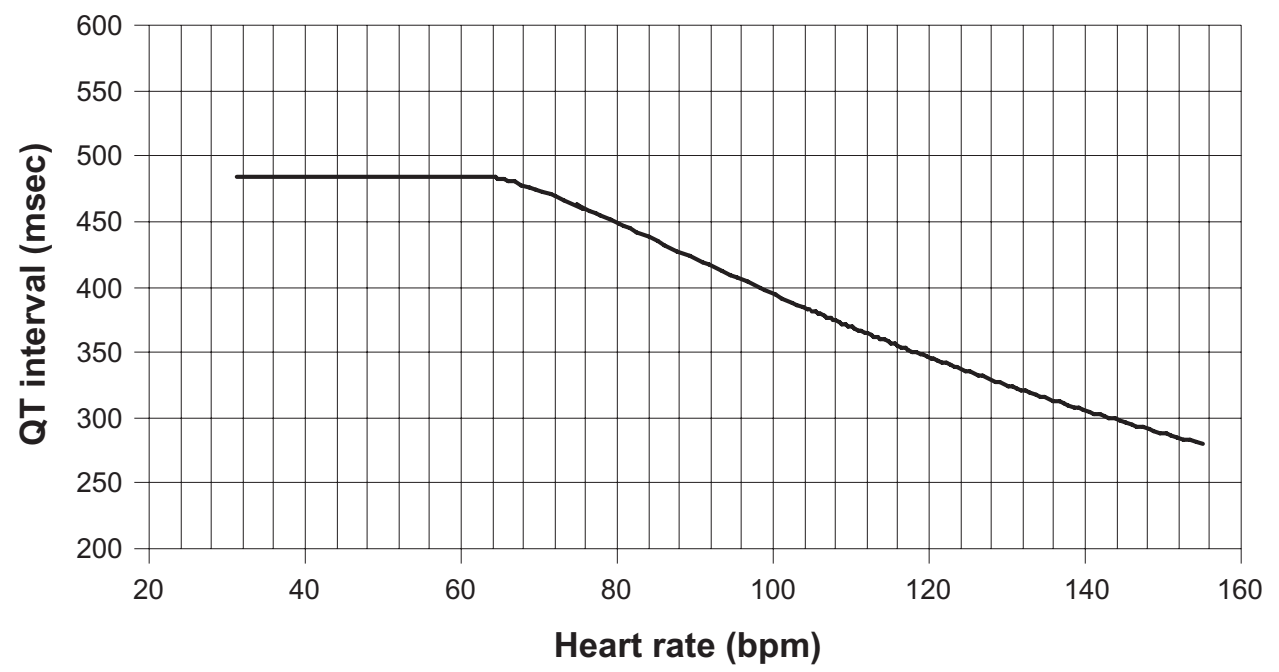

Figure 2 Nomogram used to interpret abnormally high QT values according to heart rate, as an alternative to QTc formulae. Copyright (C 2008, reproduced by permission of Oxford University Press from Chan A, Isbister GK, Kirkpatrick CM, Dufful SB. Drug-induced QT prolongation and torsades de pointes: evaluation of a QT nomogram. QJM. 2007;100:609-615. ${ }^{13}$

is required to incorporate semiautomated QT determination where the end of the $\mathrm{T}$ wave is marked manually using a mean measurement across three to five complexes, and studies are required to include a positive control and use a metabolic inhibitor. ${ }^{17}$

\section{Reference range for $\mathrm{QT}$ interval}

In contrast with the established arrhythmia risk attributable to QT prolongation, there has been recent interest in the potential for QT shortening to predispose to arrhythmia too. Familial QT shortening was first identified as a risk factor for arrhythmia in 2000, and there have been more recent reports of congenital forms of short QT intervals accompanied by arrhythmia and sudden cardiac death. ${ }^{18,19}$ The term "short QT syndrome" has recently been coined for a clinical entity associated with increased risk of arrhythmia and sudden cardiac death, and a number of underlying genetic abnormalities have been described. ${ }^{20,21}$ A large number of studies have sought to define the normal QTc range, and most have focused on defining an upper limit. For example, the first regulatory guidance indicated normal QTcB up to $450 \mathrm{msec}$ in men and $470 \mathrm{msec}$ in women. ${ }^{22}$ A large dataset of ECGs from 46,129 healthy adults indicate 2nd and 98th percentiles for QTcB of 361-457 msec, and QTcF of 359-445 msec. ${ }^{23}$ Normal QT and QTc values vary widely between individuals, and even within an individual diurnal variation may be between 76 and $102 \mathrm{msec}$. $\mathrm{QTcB}>500 \mathrm{msec}$ is considered a major risk factor for the development of TdP. ${ }^{12,17}$ More relevant is perhaps the need to establish baseline QT or QTc values prior to antidepressant therapy, so that evaluation of drug-induced changes may be permitted.

Table I Summary of various formulae used to correct QT on the basis of heart rate

\begin{tabular}{|c|c|c|c|}
\hline Formula & QTc calculation & Advantages & Disadvantages \\
\hline $\begin{array}{l}\text { Bazett } \\
\text { (QTcB) }\end{array}$ & $\mathrm{QT} /(\mathrm{R}-\mathrm{R})^{1 / 2}$ & $\begin{array}{l}\text { Widely used, performs well for } \\
\text { HR } 60-100 \text { per minute }\end{array}$ & $\begin{array}{l}\text { Overcorrects at high HR, } \\
\text { undercorrects at low HR }\end{array}$ \\
\hline $\begin{array}{l}\text { Fredricia } \\
\text { (QTcF) }\end{array}$ & $\mathrm{QT} /(\mathrm{R}-\mathrm{R})^{1 / 3}$ & $\begin{array}{l}\text { More accurate than QTcB at } \\
\text { extremes of } \mathrm{HR}\end{array}$ & Complexity of calculation \\
\hline $\begin{array}{l}\text { Hodges } \\
(\mathrm{QTcH})\end{array}$ & $\mathrm{QT}+\mathrm{I} .75(\mathrm{HR}-60)$ & $\begin{array}{l}\text { Less influenced by HR than } \\
\text { other formulae }\end{array}$ & $\begin{array}{l}\text { Reference range and } \\
\text { outcomes are poorly defined }\end{array}$ \\
\hline $\begin{array}{l}\text { Framingham } \\
\text { (QTcL) }\end{array}$ & $\mathrm{QT}+0.154 \times(\mathrm{I}-\mathrm{RR})$ & More accurate than QTcB & $\begin{array}{l}\text { Derived from single } \\
\text { population, few validation data }\end{array}$ \\
\hline $\begin{array}{l}\text { Individual } \\
\text { (QTcl) }\end{array}$ & QT/(QT-R-R slope) & $\begin{array}{l}\text { Ability to detect intraindividual } \\
\text { QT outliers }\end{array}$ & $\begin{array}{l}\text { Requires many baseline } Q T \\
\text { values across range of } R-R\end{array}$ \\
\hline Nomogram & QT "above line" & $\begin{array}{l}\text { Requires knowledge of HR and } \\
\text { QT only }\end{array}$ & $\begin{array}{l}\text { Limited validation, especially } \\
\text { HR }>110 \text { per minute }\end{array}$ \\
\hline
\end{tabular}

Note: $R-R$ is the interval between successive $R$ waves in seconds, the inverse of heart rate. 


\section{Comorbid cardiovascular risk factors}

The presence of associated depressive illness in patients with established cardiovascular disease is long recognized. Moreover, there is a considerable overlap between the risk factors that predispose to these separate disorders, including alcohol excess, cigarette smoking status, and lack of physical exercise. ${ }^{24}$ Indeed, antidepressants may independently worsen the constituent cardiovascular risk factors, such as dyslipidemia, diabetes, and metabolic syndrome. ${ }^{25}$ A common genetic risk profile has also been suggested. ${ }^{26}$ One study found that patients with major depressive disorder had a $50 \%$ increased odds of any cardiovascular diagnosis, independent of sociodemographic factors, but that this could be explained by differences in body mass index and substance misuse. ${ }^{27}$ Therefore, confounding by independent risk factors is likely to pose an important limitation to interpretation of cardiovascular outcomes in patients treated with antidepressants. Development of TdP is likely to depend on factors other than QT prolongation, eg, the presence of pre-existing cardiac disease and occurrence of ventricular ectopic beats that may predispose to the "R on T" phenomenon. ${ }^{28}$ Other ECG indices have also been proposed as markers of antidepressant-induced arrhythmia risk, namely QT dispersion, T wave alternans, and emergence of the Brugada pattern. ${ }^{29-33}$

\section{Pharmacological mechanisms responsible for cardiovascular effects \\ Tricyclic antidepressants}

This group of agents is characterized by effects on a broad range of receptor pathways that are implicated in both the therapeutic and adverse mechanisms of action. They may cause significant inhibition of central cholinergic neurotransmission, which results in a number of widespread autonomic features, including tachycardia. ${ }^{34}$ This is accompanied by impaired neuronal uptake of norepinephrine, which may worsen tachycardia. Tricyclic antidepressants are capable of blocking alpha-adrenergic receptors, and this may lower systemic vascular resistance and result in hypotension, or orthostatic hypotension. ${ }^{35}$ High tricyclic doses increase sympathetic and decrease parasympathetic influence on heart rate variability. ${ }^{36}$ Tricyclic antidepressants also inhibit sodium channel conductance, so that phase 0 cardiac depolarization is delayed. ${ }^{37}$ This may cause slower conduction within the His-Purkinje fibers and ventricular myocardium, causing prolongation of the QRS complex on the ECG. ${ }^{38}$

\section{Selective serotonin reuptake inhibitors}

This group of antidepressants is thought to cause cardiovascular effects predominantly through excess serotonin release within the central nervous system, which may manifest in mild systemic hypotension. ${ }^{39}$ Both citalopram and escitalopram are capable of provoking generalized seizures. ${ }^{40,41}$ Citalopram and escitalopram are known to cause dose-dependent QT prolongation, although the mechanism remains uncertain and may be unrelated to serotonin reuptake per se. ${ }^{1,2}$ Fewer data exist concerning the occurrence of QT prolongation with other selective serotonin reuptake inhibitor agents.

\section{Monoamine oxidase inhibitors}

These agents result in enhanced concentrations of a broad range of central neurotransmitters, including norepinephrine. ${ }^{42}$ This may result in tachycardia and raised blood pressure, particularly if used in high doses. The onset of cardiovascular effects may be delayed by up to 12-24 hours after exposure to high monoamine oxidase inhibitor concentrations because of the time taken for accumulation of central neurotransmitter concentrations. Coingestion of medications or foodstuffs rich in tyramine may precipitate a severe rise in blood pressure, ie, the so-called "cheese reaction". Monoamine oxidase inhibitors may also cause cardiovascular effects mediated by serotonin accumulation, including tachycardia and hypotension, especially if used in combination with a tricyclic antidepressant or selective serotonin reuptake inhibitor. ${ }^{43}$

\section{Serotonin and norepinephrine reuptake inhibitors}

Venlafaxine, reboxetine, and duloxetine appear capable of stimulating cardiac sympathetic activity, which may manifest as a modest increase in heart rate and systemic blood pressure. ${ }^{44,45}$ For example, duloxetine increases peripheral norepinephrine concentrations and sympathetic tone, and reboxetine has been shown to increase sympathetic influence on heart rate variability. ${ }^{46,47}$ Excess sympathetic activity might predispose to an increased risk of more serious tachyarrhythmia, as identified in the context of cardiomyopathy. ${ }^{48}$ Venlafaxine is capable of blocking cardiac sodium channel conductance, similar to tricyclic antidepressants, and there is some evidence that toxic doses may cause elevated systemic blood pressure and QT prolongation. ${ }^{49,50}$ Venlafaxine causes a dose-dependent increase in systemic blood pressure, but there are too few data 
available to ascertain the rate of occurrence of arrhythmia arising after therapeutic doses. ${ }^{51}$

\section{Differential risk between antidepressant classes Tricyclics}

Tricyclics are undoubtedly associated with high cardiovascular morbidity and mortality in overdose, including development of QTcB prolongation and TdP. ${ }^{52-54}$ Nonetheless, the relationship between normal therapeutic administration and occurrence of serious arrhythmia is less certain. Some studies have reported a relationship between initiation of tricyclic therapy and minor prolongation of the QT interval by up to $0-20 \mathrm{msec}$, with similar values reported between the different tricyclics. ${ }^{55-57}$ However, these observations are heavily confounded by other factors that might independently increase risk, including family history of congenital long QT syndrome, increased age, female sex, the presence of metabolic and cardiovascular disease, hypokalemia, and coadministration of drugs independently associated with QT interval prolongation, including thioridazine and fluconazole, or that interact with the antidepressant to increase arrhythmia risk. ${ }^{57,58}$ In one report, short-term administration of amitriptyline in patients with depression was associated with QRS and QTcB prolongation. ${ }^{59}$ Tachycardia is a recognized anticholinergic feature of tricyclics, which is an important confounding factor that could result in overcorrection of QT by the Bazett formula or other formulae.

Experimental laboratory approaches have produced conflicting data that have not resolved the issue. For example, a study on in vivo Purkinje fibers found that imipramine and dothiepin were capable of inducing early after-depolarizations, an early step in development of TdP, but only in the presence of hypokalemia, whereas amitriptyline did not. ${ }^{60}$ An ex vivo study on HERG conductance found that nortriptyline did not affect QTcB at doses equivalent to $2 \mathrm{mg} / \mathrm{kg}$ or $6 \mathrm{mg} / \mathrm{kg}$, but caused a modest increase at $20 \mathrm{mg} / \mathrm{kg}$; these findings suggest that nortriptyline is unlikely to exert a significant effect on ventricular repolarization at therapeutic dosages. ${ }^{61}$ In contrast, clomipramine is capable of blocking HERG conduction at concentrations similar to those observed after therapeutic dosages, perhaps suggesting different effects within the same drug group. ${ }^{62}$

\section{Selective serotonin reuptake inhibitors}

A number of reports have been published after the approval of various selective serotonin reuptake inhibitor agents that indicate an association with QTc prolongation or TdP. For example, analyses of the Swedish pharmacovigilance database found that citalopram was associated with around $10 \%$ of occurrences of $\mathrm{TdP}^{63}$ Most of the reported cases involve QTcB prolongation or arrhythmia that occurs after toxic doses, such as might only be encountered after deliberate drug overdose. ${ }^{64-67}$

In other reports, cardiac effects have been found to occur when a selective serotonin reuptake inhibitor has been administered in combination with other drugs that are independently capable of prolonging QTc. ${ }^{68,69}$ Elsewhere, the association between selective serotonin reuptake inhibitor administration and the occurrence of QTc prolongation may be explained by the coexistence of other factors, including hypokalemia and hypomagnesemia. ${ }^{70,71}$ The change in QTcB associated with selective serotonin reuptake inhibitor use is reported to lie between a $5 \mathrm{msec}$ decrease and a $10 \mathrm{msec}$ increase in population studies. ${ }^{72}$

The greatest body of evidence of QTc prolongation is that concerning citalopram, particularly in the setting of overdose but also in a number of case reports involving therapeutic administration. For example, treatment with citalopram $40 \mathrm{mg}$ twice daily was associated with prolonged QTcB and development of TdP in a 40-year-old woman, in whom no other metabolic disturbance or causative factor could be identified; QTcB fell from $535 \mathrm{msec}$ to $469 \mathrm{msec}$ three days after citalopram was discontinued. ${ }^{73} \mathrm{~A}$ further report indicates that therapeutic citalopram administration caused severe prolongation of QT and QTcB (572 $\mathrm{msec}$ and $695 \mathrm{msec}$, respectively) in a female patient who developed TdP; the QTcB normalized 3 days after citalopram discontinuation. ${ }^{74}$ Escitalopram, the S-enantiomer of citalopram, has been reported to cause significant reversible QTcB prolongation, even after only two daily administrations of $5 \mathrm{mg} .{ }^{75}$ Data from a thorough QT study was recently presented by regulatory authorities showing a dose-dependent increase in QTcB and QTcF within the therapeutic range. ${ }^{1,2}$

\section{Serotonin and norepinephrine reuptake inhibitors}

Venlafaxine administration has been associated with QTc prolongation in a 68 -year-old woman that normalized several days after drug cessation (QTcB $582 \mathrm{msec}$ ); however, this was confounded by the presence of hypertension and possible cardiac failure ${ }^{76}$ High doses of reboxetine in healthy adults have no apparent effect on QT or QT corrected by a number of different methods, although heart rate increased by $8-11$ beats per minute from baseline. ${ }^{77}$ 


\section{Monoamine oxidase inhibitors}

Tranylcypromine may cause a modest fall in diastolic blood pressure and symptomatic hypotension. ${ }^{78}$ Phenelzine has been noted to cause acute myocarditis after intentional overdose, but this has not been reported after therapeutic administration. ${ }^{79}$ QTcB prolongation has been described in patients who present to hospital after intentional moclobemide overdose, but such similar data have not been examined systematically in patients receiving therapeutic doses. ${ }^{80}$

\section{Others}

Mirtazapine appears capable of causing only minor cardiovascular effects, and toxic doses have been reported to cause inconsistent effects on heart rate and mild hypotension. ${ }^{81-83}$ Trazodone may be associated with orthostatic hypotension, particularly in high doses, and QTcB prolongation has been reported as a feature of trazodone toxicity. ${ }^{84-86}$

Lithium may be associated with a number of different cardiac conduction defects, including complete heart block and impaired atrioventricular conduction; onset of cardiac toxicity might be delayed after exposure to high concentrations due to the delay in equilibration of cardiac tissue concentrations. ${ }^{87-90}$ High lithium concentrations $>1.2 \mathrm{mmol} / \mathrm{L}$ have been reported to increase the risk of QTcB prolongation. ${ }^{91}$

\section{Risk-benefit assessment}

A wide variety of antidepressant agents are now available, and the cardiovascular profile of each of these is characterized to a variable extent. The overall balance between risk and benefit of therapy needs to consider the strength of the indication for antidepressant treatment, pre-existing risk factors for cardiovascular disease, drug dose, and perceived risk of inadvertent or intentional drug overdose. Well characterized effects of the monoamine oxidase inhibitor group and of trazodone include orthostatic hypotension, whilst the tricyclic antidepressant group are typically associated with tachycardia and a modest fall in systemic blood pressure. Serotonin and norepinephrine reuptake inhibitor agents may cause tachycardia and a modest rise in systemic blood pressure within the therapeutic dose range, whereas selective serotonin reuptake inhibitor agents exert few consistent cardiovascular effects; within the selective serotonin reuptake inhibitor group, citalopram and escitalopram appear uniquely capable of causing dose-dependent QTc prolongation. These various cardiovascular effects will allow the choice of antidepressant agent to be determined according to the individual patient characteristics and risk profile so that, for example, venlafaxine might be avoided in a patient with borderline systemic hypertension, and citalopram should be avoided in a patient receiving other medications capable of prolonging QTc.

\section{Gaps in current understanding}

At present, there is an unmet need for evidence-based guidance in two key areas. Firstly, there is a lack of data to inform the optimal choice of antidepressant agent that might minimize the risk of arrhythmia, particularly in those patients at greatest risk due to the presence of pre-existing cardiovascular disease or major cardiovascular risk factors. This is likely to require large prospective clinical studies with detailed cardiovascular monitoring in appropriately selected highrisk patient groups, but might also be addressed, at least in part, by pooled subset analyses of data from existing studies. Secondly, there is a pressing need to develop consistent guidance concerning what measurement to use in determining potential arrhythmia risk and the optimum intensity of monitoring. Too few data exist to allow an evidence-based approach to be determined. Nonetheless, it may be feasible for regulatory authorities and appropriate learned bodies to produce consensus statements concerning what to monitor and how, so that greater consistency could be applied in clinical practice.

\section{Conclusion}

The existing data indicate that certain antidepressant agents are associated with an increased burden of cardiac toxicity and this is often related to the presence of pre-existing cardiac disease or other factors that might independently increase the risk of arrhythmia. Cardiotoxicity is readily apparent in the context of intentional antidepressant overdose, whereas fewer data exist concerning adverse cardiac effects occurring due to therapeutic administration. Clinical judgment is needed on a patient by patient basis to consider carefully the overall risks and benefits of individual antidepressant agents, and there is a lack of robust evidence to guide clinical practice. In those with pre-existing cardiovascular disease or those with major risk factors such as hypertension and diabetes, it would be prudent to perform an ECG before and soon after starting therapy to allow detection of QT prolongation or other abnormalities. The lack of any significant ECG effect may offer some clinical reassurance that antidepressant treatment does not pose a significant risk of arrhythmia, and could be subject to periodic observation at the discretion of the treating clinician. Alternatively, the occurrence of a substantial ECG abnormality, for example QTcB > $500 \mathrm{msec}$, may indicate an increased risk of arrhythmia, so that the antidepressant 
could be stopped and an alternative agent considered, or the dose could be reduced with further ECG monitoring.

\section{Disclosure}

The author reports no conflict of interest in this work.

\section{References}

1. Medicines and Healthcare products Regulatory Authority. Citalopram and escitalopram: QT interval prolongation: New maximum daily dose restrictions (including in elderly patients), contraindications, and warnings. Available from: http://www.mhra.gov.uk/Safetyinformation/ DrugSafetyUpdate/CON137769. Accessed July 27, 2012.

2. Food and Drug Administration. FDA Drug Safety Communication: Revised recommendations for Celexa (citalopram hydrobromide) related to a potential risk of abnormal heart rhythms with high doses. Available from: http://www.fda.gov/Drugs/DrugSafety/ucm297391.htm. Accessed July 27, 2012.

3. Howland RH. A critical evaluation of the cardiac toxicity of citalopram: part 2. J Psychosoc Nurs Ment Health Serv. 2011;49:13-16.

4. Leonard CE, Bilker WB, Newcomb C, Kimmel SE, Hennessy S. Antidepressants and the risk of sudden cardiac death and ventricular arrhythmia. Pharmacoepidemiol Drug Saf. 2011;20:903-913.

5. Gintant G. An evaluation of hERG current assay performance: Translating preclinical safety studies to clinical QT prolongation. Pharmacol Ther. 2011;129:109-119.

6. Shimizu W, Horie M. Phenotypic manifestations of mutations in genes encoding subunits of cardiac potassium channels. Circ Res. 2011;109: 97-109.

7. Kallergis EM, Goudis CA, Simantirakis EN, Kochiadakis GE, Vardas PE. Mechanisms, risk factors, and management of acquired long QT syndrome: a comprehensive review. Scientific World Journal. 2012; 2012:212178.

8. Sauer AJ, Newton-Cheh C. Clinical and genetic determinants of torsade de pointes risk. Circulation. 2012;125:1684-1694.

9. Owens RC Jr, Nolin TD. Antimicrobial-associated QT interval prolongation: pointes of interest. Clin Infect Dis. 2006;43:1603-1611.

10. Chung AK, Chua SE. Effects on prolongation of Bazett's corrected QT interval of seven second-generation antipsychotics in the treatment of schizophrenia: a meta-analysis. J Psychopharmacol. 2011;25: 646-666.

11. Thomas SH, Drici MD, Hall GC, et al. Safety of sertindole versus risperidone in schizophrenia: principal results of the sertindole cohort prospective study (SCoP). Acta Psychiatr Scand. 2010;122: $345-355$.

12. Malik M, Hnatkova K, Sisakova M, Schmidt G. Subject-specific heart rate dependency of electrocardiographic QT, PQ, and QRS intervals. J Electrocardiol. 2008;41:491-497.

13. Chan A, Isbister GK, Kirkpatrick CM, Dufful SB. Drug-induced QT prolongation and torsades de pointes: evaluation of a QT nomogram. QJM. 2007;100:609-615.

14. Waring WS, Graham A, Gray J, Wilson AD, Howell C, Bateman DN. Evaluation of a QT nomogram for risk assessment after antidepressant overdose. Br J Clin Pharmacol. 2010;70:881-885.

15. Extramiana F, Maison-Blanche P, Cabanis MJ, Ortemann-Renon C, Beaufils P, Leenhardt A. Clinical assessment of drug-induced QT prolongation in association with heart rate changes. Clin Pharmacol Ther. 2005;77:247-258.

16. Luo S, Michler K, Johnston P, MacFarlane PW. A comparison of commonly used QT correction formulae: the effect of heart rate on the QTc of normal ECGs. J Electrocardiol. 2004;37 Suppl:81-90.

17. Kannankeril PJ, Roden DM. Drug-induced long QT and torsade de pointes: recent advances. Curr Opin Cardiol. 2007;22:39-43.

18. Gussak I, Brugada P, Brugada J, et al. Idiopathic short QT interval: a new clinical syndrome? Cardiology. 2000;94:99-102.
19. Gaita F, Giustetto C, Bianchi F, et al. Short QT syndrome: a familial cause of sudden death. Circulation. 2003;108:965-970.

20. Brugada R, Hong K, Dumaine R, et al. Sudden death associated with short-QT syndrome linked to mutations in HERG. Circulation. 2004;109: 30-35.

21. Priori SG, Pandit SV, Rivolta I, et al. A novel form of short QT syndrome SQT3 is caused by a mutation in the KCNJ2 gene. Circ Res. 2005;96: 800-807.

22. Committee for Proprietary Medicinal Products. Points to consider: the assessment of the potential for QT interval prolongation by noncardiovascular medicinal products (CPMP/986/96) London, UK: EMEA; 1997. Available from: http://www.fda.gov/ohrms/dockets/ ac/03/briefing/pubs\%5Ccpmp.pdf. Accessed July 27, 2012.

23. Mason JW, Ramseth DJ, Chanter DO, Moon TE, Goodman DB, Mendzelevski B. Electrocardiographic reference ranges derived from 79,743 ambulatory subjects. J Electrocardiol. 2007;40:228-234.

24. Labad J, Price JF, Strachan MW, et al. Symptoms of depression but not anxiety are associated with central obesity and cardiovascular disease in people with type 2 diabetes: the Edinburgh Type 2 Diabetes Study. Diabetologia. 2010;53:467-471.

25. McIntyre RS, Park KY, Law CW, et al. The association between conventional antidepressants and the metabolic syndrome: a review of the evidence and clinical implications. CNS Drugs. 2010;24:741-753.

26. López-León S, Aulchenko YS, Tiemeier H, Oostra BA, van Duijn CM, Janssens AC. Shared genetic factors in the co-occurrence of symptoms of depression and cardiovascular risk factors. JAffect Disord. 2010;122: $247-252$.

27. Niranjan A, Corujo A, Ziegelstein RC, Nwulia E. Depression and heart disease in US adults. Gen Hosp Psychiatry. 2012;34:254-261.

28. Miyazaki S, Shah AJ, Haïssaguerre M. Early repolarization syndrome: a new electrical disorder associated with sudden cardiac death. Circ J. 2010;74:2039-2044.

29. Havránek S, Micek M, Paclt I, et al. QT dispersion estimated from 80 body surface potential map leads and from standard 12-leads ECG in psychiatric patients treated with dosulepin. Prague Med Rep. 2004;105: 53-63.

30. Nielsen J, Andersen MP, Graff C, et al. The effect of sertindole on QTD and TPTE. Acta Psychiatr Scand. 2010;121:385-388.

31. Raviña T, Suarez ML, Mendez-Castrillón J. Fluoxetine-induced QTU interval prolongation, T wave alternans and syncope. Int J Cardiol. 1998; 65:311-313.

32. Meert A, Vermeersch N, Beckers R, Hoste W, Brugada P, Hubloue I. Brugada-like ECG pattern induced by tricyclic antidepressants. Eur J Emerg Med. 2010;17:325-327.

33. Stirnimann G, Petitprez S, Abriel H, Schwick NG. Brugada syndrome ECG provoked by the selective serotonin reuptake inhibitor fluvoxamine. Europace. 2010;12:282-283.

34. Thanacoody HK, Thomas SH. Tricyclic antidepressant poisoning: cardiovascular toxicity. Toxicol Rev. 2005;24:205-214.

35. Lee MY, Kim SJ, Kim JS, Kang HS. Imipramine-induced cardiac depression is responsible for the increase in intracellular magnesium and the activation of ERK 1/2 in rats. J Cardiovasc Pharmacol Ther. 2010;15: 303-310.

36. Waring WS, Rhee JY, Bateman DN, Leggett GE, Jamie H. Impaired heart rate variability and altered cardiac sympathovagal balance after antidepressant overdose. Eur J Clin Pharmacol. 2008;64: 1037-1041.

37. Yang YC, Huang CS, Kuo CC. Lidocaine, carbamazepine, and imipramine have partially overlapping binding sites and additive inhibitory effect on neuronal Na+ channels. Anesthesiology. 2010;113:160-174.

38. Bradberry SM, Thanacoody HK, Watt BE, Thomas SH, Vale JA. Management of the cardiovascular complications of tricyclic antidepressant poisoning: role of sodium bicarbonate. Toxicol Rev. 2005;24: $195-204$.

39. Linder AE, Diaz J, Ni W, Szasz T, Burnett R, Watts SW. Vascular reactivity, 5-HT uptake, and blood pressure in the serotonin transporter knockout rat. Am J Physiol Heart Circ Physiol. 2008;294:H1745-H1752. 
40. Yilmaz Z, Ceschi A, Rauber-Lüthy C, et al. Escitalopram causes fewer seizures in human overdose than citalopram. Clin Toxicol. 2010;48: 207-212.

41. Waring WS, Gray JA, Graham A. Predictive factors for generalized seizures after deliberate citalopram overdose. Br J Clin Pharmacol. 2008; 66:861-865

42. Pelat M, Verwaerde P, Tran MA, Berlan M, Senard JM, Montastruc JL. Changes in vascular alpha 1- and alpha 2-adrenoceptor responsiveness by selegiline treatment. Fundam Clin Pharmacol. 2001;15:239-245.

43. Riederer P, Lachenmayer L, Laux G. Clinical applications of MAOinhibitors. Curr Med Chem. 2004;11:2033-2043.

44. Rudolph RL, Derivan AT. The safety and tolerability of venlafaxine hydrochloride: analysis of the clinical trials database. J Clin Psychopharmacol. 1996;16:54S-59S.

45. Ferini-Strambi L, Manconi M, Castronovo V, Riva L, Bianchi A. Effects of reboxetine on sleep and nocturnal cardiac autonomic activity in patients with dysthymia. J Psychopharmacol. 2004;18:417-422.

46. Chalon SA, Granier LA, Vandenhende FR, et al. Duloxetine increases serotonin and norepinephrine availability in healthy subjects: a double-blind, controlled study. Neuropsychopharmacology. 2003;28:1685-1693.

47. Agelink MW, Ullrich H, Baumann B, Strum S, Majewski T. Effects of reboxetine, a selective norepinephrine reuptake inhibitor, on sympathetic and parasympathetic outflow to the heart: preliminary data. Psychopharmacology. 2002;163:151-156.

48. Paul M, Wichter T, Kies P, et al. Cardiac sympathetic dysfunction in genotyped patients with arrhythmogenic right ventricular cardiomyopathy and risk of recurrent ventricular tachyarrhythmias. J Nucl Med. 2011;52:1559-1565.

49. Khalifa M, Daleau P, Turgeon J. Mechanism of sodium channel block by venlafaxine in guinea pig ventricular myocytes. J Pharmacol Exp Ther. 1999;291:280-284.

50. Howell C, Wilson AD, Waring WS. Cardiovascular toxicity due to venlafaxine poisoning in adults: a review of 235 consecutive cases. $\mathrm{Br}$ J Clin Pharmacol. 2007;64:192-197.

51. Mbaya P, Alam F, Ashim S, Bennett D. Cardiovascular effects of high dose venlafaxine XL in patients with major depressive disorder. Hum Psychopharmacol. 2007;22:129-133.

52. Chan CY, Waring WS. Images in cardiovascular medicine. Tricyclic cardiotoxicity treated with sodium bicarbonate. Circulation. 2007;115: e63-e64.

53. Davison ET. Amitriptyline-induced torsade de pointes. Successful therapy with atrial pacing. J Electrocardiol. 1985;18:299-301.

54. Alter P, Tontsch D, Grimm W. Doxepin-induced torsade de pointes tachycardia. Ann Intern Med. 2001;135:384-385.

55. van Noord C, Straus S, Sturkenboom M et al. Psychotropic drugs associated with corrected QT interval prolongation. J Clin Psychopharmacol. 2009;29:9-15.

56. Goodnick PJ, Jerry J, Parra F. Psychotropic drugs and the ECG: focus on the QTc interval. Expert Opin Pharmacother. 2002;3:479-498.

57. Vieweg WV, Wood MA. Tricyclic antidepressants, QT interval prolongation, and torsade de pointes. Psychosomatics. 2004;45: 371-377.

58. Dorsey ST, Biblo LA. Prolonged QT interval and torsades de pointes caused by the combination of fluconazole and amitriptyline. Am J Emerg Med. 2000;18:227-229.

59. Robinson DS, Nies A, Corcella J, Cooper TB, Spencer C, Keefover R. Cardiovascular effects of phenelzine and amitriptyline in depressed outpatients. J Clin Psychiatry. 1982;43:8-15.

60. Studenik C, Lemmens-Gruber R, Heistracher P. Proarrhythmic effects of antidepressants and neuroleptic drugs on isolated, spontaneously beating guinea-pig Purkinje fibers. Eur J Pharm Sci. 1999;7:113-118.

61. Jeon SH, Jaekal J, Lee SH, et al. Effects of nortriptyline on QT prolongation: a safety pharmacology study. Hum Exp Toxicol. 2011;30: 1649-1656.

62. Jo SH, Hong HK, Chong SH, Won KH, Jung SJ, Choe H. Clomipramine block of the hERG K+ channel: accessibility to F656 and Y652. Eur J Pharmacol. 2008;592:19-25.
63. Aström-Lilja C, Odeberg JM, Ekman E, Hägg S. Drug-induced torsades de pointes: a review of the Swedish pharmacovigilance database. Pharmacoepidemiol Drug Saf. 2008;17:587-592.

64. Tarabar AF, Hoffman RS, Nelson L. Citalopram overdose: late presentation of torsades de pointes (TdP) with cardiac arrest. $J$ Med Toxicol. 2008;4:101-105.

65. Lherm T, Lottin F, Larbi D, Bray M, Legall C, Caen D. Torsade de pointes after poisoning with fluoxetine alone. Presse Med. 2000;29: 306-307. French.

66. Mohammed R, Norton J, Geraci SA, Newman DB, Koch CA. Prolonged QTc interval due to escitalopram overdose. J Miss State Med Assoc. 2010;51:350-353.

67. Baranchuk A, Simpson CS, Methot M, Gibson K, Strum D. Corrected QT interval prolongation after an overdose of escitalopram, morphine, oxycodone, zopiclone and benzodiazepines. Can J Cardiol. 2008;24: e38-e40.

68. Fayssoil A, Issi J, Guerbaa M, Raynaud JC, Heroguelle V. Torsade de pointes induced by citalopram and amiodarone. Ann Cardiol Angeiol. 2011;60:165-168. French.

69. Blaschke D, Parwani AS, Huemer M, et al. Torsade de pointes during combined treatment with risperidone and citalopram. Pharmacopsychiatry. 2007;40:294-295.

70. Digby G, Machaalany J, Malik P, et al. Multifactorial QT interval prolongation. Cardiol J. 2010;17:184-188.

71. Wenzel-Seifert K, Wittmann M, Haen E. Torsade de pointes episodes under treatment with selective serotonin reuptake inhibitors. Pharmacopsychiatry. 2010;43:279-281.

72. Wenzel-Seifert K, Wittmann M, Haen E. QTc prolongation by psychotropic drugs and the risk of torsade de pointes. Dtsch Arztebl Int. 2011;108:687-693.

73. Deshmukh A, Ulveling K, Alla V, Abuissa H, Airey K. Prolonged QTc interval and torsades de pointes induced by citalopram. Tex Heart Inst J. 2012;39:68-70.

74. Kanjanauthai S, Kanluen T, Chareonthaitawee P. Citalopram induced torsade de pointes, a rare life threatening side effect. Int $J$ Cardiol. 2008;131:e33-e34.

75. Tseng PT, Lee Y, Lin YE, Lin PY. Low-dose escitalopram for 2 days associated with corrected QT interval prolongation in a middle-aged woman: a case report and literature review. Gen Hosp Psychiatry. 2012; 34:210. e13-e15.

76. Letsas K, Korantzopoulos P, Pappas L, Evangelou D, Efremidis M, Kardaras F. QT interval prolongation associated with venlafaxine administration. Int $J$ Cardiol. 2006;109:116-117.

77. Fleishaker JC, Francom SF, Herman BD, Knuth DW, Azie NE. Lack of effect of reboxetine on cardiac repolarization. Clin Pharmacol Ther. 2001;70:261-269.

78. O’Brien S, McKeon P, O'Regan M, O'Flaherty A, Patel R. Blood pressure effects of tranylcypromine when prescribed singly and in combination with amitriptyline. J Clin Psychopharmacol. 1992;12: 104-109.

79. Waring WS, Wallace WA. Acute myocarditis after massive phenelzine overdose. Eur J Clin Pharmacol. 2007;63:1007-1009.

80. Downes MA, Whyte IM, Isbister GK. QTc abnormalities in deliberate self-poisoning with moclobemide. Intern Med J. 2005;35:388-391.

81. Poluzzi E, Raschi E, Moretti U, De Ponti F. Drug-induced torsades de pointes: data mining of the public version of the FDA adverse event reporting system (AERS). Pharmacoepidemiol Drug Saf. 2009;18: 512-518.

82. LoVecchio F, Riley B, Pizon A, Brown M. Outcomes after isolated mirtazapine(Remeron) supratherapeutic ingestions.JEmerg Med.2008;34: 77-78.

83. Waring WS, Good AM, Bateman DN. Lack of significant toxicity after mirtazapine overdose: a five-year review of cases admitted to a regional toxicology unit. Clin Toxicol. 2007;45:45-50.

84. Krahn LE, Hanson CA, Pileggi TS, Rummans TA. Electroconvulsive therapy and cardiovascular complications in patients taking trazodone for insomnia. J Clin Psychiatry. 2001;62:108-110. 
85. Haria M, Fitton A, McTavish D. Trazodone. A review of its pharmacology, therapeutic use in depression and therapeutic potential in other disorders. Drugs Aging. 1994;4:331-355.

86. Service JA, Waring WS. QT Prolongation and delayed atrioventricular conduction caused by acute ingestion of trazodone. Clin Toxicol. 2008; 46:71-73.

87. Waring WS. Delayed cardiotoxicity in chronic lithium poisoning: discrepancy between serum lithium concentrations and clinical status. Basic Clin Pharmacol Toxicol. 2007;100:353-355.

88. Waring WS, Laing WJ, Good AM, Bateman DN. Pattern of lithium exposure predicts poisoning severity: evaluation of referrals to a regional poisons unit. QJM. 2007;100:271-276.
89. Talati SN, Aslam AF, Vasavada B. Sinus node dysfunction in association with chronic lithium therapy: a case report and review of literature. Am J Ther. 2009;16:274-278.

90. Kayrak M, Duman C, Gul EE, Sonmez O, Kaya Z, Ari H. A bizarre electrocardiographic pattern due to chronic lithium therapy. Ann Noninvasive Electrocardiol. 2010;15:289-292.

91. Hsu CH, Liu PY, Chen JH, Yeh TL, Tsai HY, Lin LJ. Electrocardiographic abnormalities as predictors for over-range lithium levels. Cardiology. 2005;103:101-106.

\section{Publish your work in this journal}

Drug, Healthcare and Patient Safety is an international, peer-reviewed open-access journal exploring patient safety issues in the healthcare continuum from diagnostic and screening interventions through to treatment, drug therapy and surgery. The journal is characterized by the rapic reporting of reviews, original research, clinical, epidemiological and

\section{Dovepress}

post-marketing surveillance studies, risk management, health literacy and educational programs across all areas of healthcare delivery. The manuscript management system is completely online and includes a very quick and fair peer-review system. Visit http://www.dovepress.com/ testimonials.php to read real quotes from published authors.

Submit your manuscript here: http://www.dovepress.com/drug-healthcare-and-patient-safety-journal 